\title{
Effect of Delay In Starting Adequate Treatment On Recovery Time Of Head And Neck Space Infections
}

\author{
Hasan $\mathrm{S}^{1}$, Khan $\mathrm{S} \mathrm{H}^{2}$, Arefin $\mathrm{R}^{3}$, Kamruzzaman $\mathrm{M}^{4}$
}

Received: 22.04.17

Accepted: 25.01 .18

Abstract:

Aim: This prospective observational study was conducted to find out "delay of starting adequate treatment" as a prognosis predictor of head and neck space infections.

Material and method:50 patients were selected purposively with inclusion criteria of presence of head and neck space infections. The exclusion criteria was presence of any other co-morbid diseases. After proper evaluation and diagnosis, adequate treatment was provided. Structured questioner method was used to collect data related to delay of starting of treatment and outcome of disease.

Result: In this prospective observational study, caries was the most frequent cause of space infection. Time elapsed in between starting of symptoms and initiation of adequate treatment (timing of starting treatment) was 8.52( \pm 6.689$)$ days. This delay of starting treatment causing increased recovery time significantly ( $P=<0.001$ level). However, there was no correlation in between delay of starting treatment and number of involved space infection but later has impact on recovery time.

Conclusion: Information about delay of starting treatment and number of involved spaces can be used as a prognosis predictor in $\mathrm{HNSI}$.

Key word: HNSI- Head and neck space infection

1. Dr. Sajid hasan, BDS, FCPS, Junior consultant, Oral and maxillofacial Surgery, BIRDEM general hospital

2. Dr. Saeed Hossain khan, BDS, FCPS, Assistant Professor, Orthodontics and Dentofacial orthopedics, BIRDEM general hospital.

3. Dr Raihan-UI Arefin,BDS, MCPS, MS, FCPS, Dental Surgeon, Upazilla Health Complex, Hatiya, Noakhali 4. Dr. Mohammad Kamruzzaman, BDS, FCPS, Assistant Professor and Head,Oral and Maxillofacial Surgery department, Update Dental College and Hospital.

Correspondence : Dr. Sajid hasan,Ph.+8801717054471, Email: dr.sazidhasan@gmail.com 


\section{Introduction:}

Head \& Neck space infections are those infections (cellulitis or abscess) which involve potential fascial compartments that contain loose connective tissue of this region. The spaces are buccal, infraorbital, temporal (superficial and deep), submandibular, submental, sublingual, pterygomandibular, submasseteric, lateral pharyngeal, retropharyngeal and pretracheal ${ }^{1}$.

The common aetiology of space infections is mainly odontogenic that is pulp and periodontal disease. Other causes are trauma and fracture, implant, infective sinusitis ${ }^{2,3}$.

The patients are usually presenting with complaints of rapid progressing pain, swelling and occasionally pus discharging sinus. Clinically there is a causative source can be found in most of the times.

The primary treatment of head-Neck space infections has been surgical drainage and antibiotic therapy. Among the antibiotics penicillin, cephalosporins, metronidazole (alone or combined with a $\beta$-lactum), clindamycine, carbapenems and $\beta$-lactum combined with $\beta$-lactamase inhibitors are proved very effective. Some other antibiotics like macrolides, tetracyclines and quinolones are effective. Among those commonly used antibiotics are penicillin, cephalosporins, metronidazole and clindamycine. With adequate treatment patient usually responds within 24-48 hours and require minimum about 7 days to a long period to cure depending on various factor of disease ${ }^{4}$.

In this study, we tried to find out any relation in between timing of starting adequate treatment and recovery time of head and neck space infection.

\section{Materials and method:}

This prospective observational study was conducted in the Department of Oral \& Maxillofacial Surgery, Bangabandhu Sheikh Mujib Medical University, Shahbag, Dhaka-1000 from 21/10/12 to $31 / 08 / 13$ on 50 OPD patients of head and neck space infection. The inclusion criteria was presence of head and neck space infections and the exclusion criteria was presence of any other co-morbid diseases. After proper evaluation and diagnosis adequate treatment was provided. The treatment was introduction of an empirical broad spectrum antibiotic and Metronidazole followed by incision and drainage of affected spaces under local anaesthesia. Drainage were further facili- tated by introduction of drain tube and repeated dressing regularly. Antibiotic was changed further according to culture and sensitivity.

A structured questioner method was used to necessary data including delay of starting of treatment and recovery time of the patients.

\section{Result:}

The results of the current study can best be presented under the following way.

Fig-1: Distribution of patients according to timing of starting adequate treatment

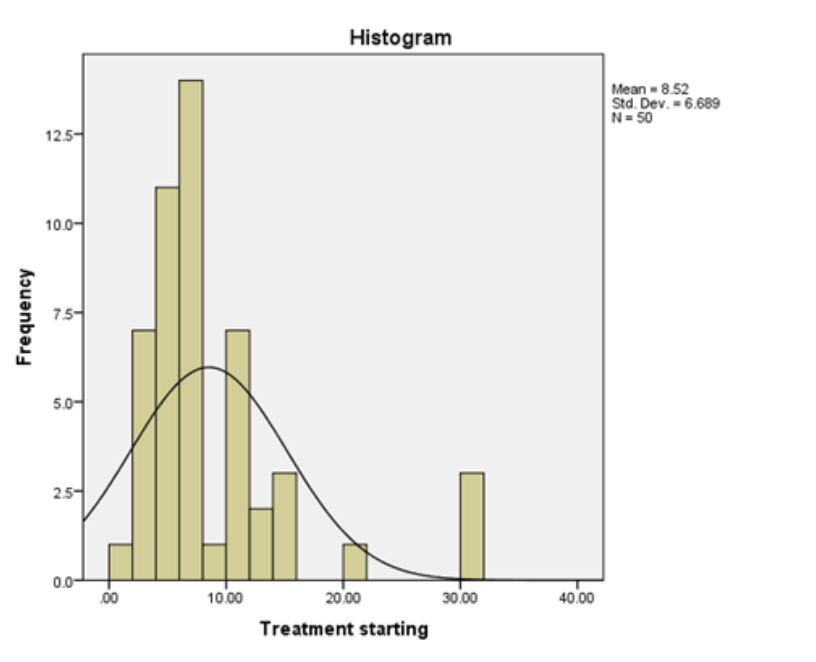

Figure- 1 shows that among the fifty patients of this study, the mean timing of starting adequate treatment was $8.52( \pm 6.689)$ days.

Table-1: Distribution of the study patients according to clinical cause of infection $(n=50)$.

\begin{tabular}{lll}
\hline Clinical cause & No of patients Percentage (\%) \\
\hline Caries & 30 & 60.0 \\
Pericoronitis & 4 & 8.0 \\
Periodontitis & 4 & 8.0 \\
Others & 12 & 24.0 \\
Total & 50 & 100.0 \\
\hline
\end{tabular}

Considering the cause of infection, caries $(60 \%$, $\mathrm{n}=30$ ) was the most common (table-1). 
Fig-2- Involved space and timing of starting treatment

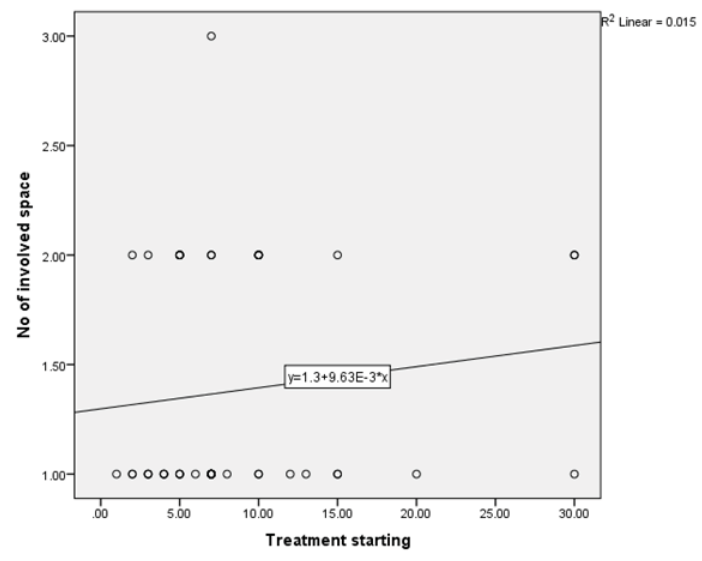

Regarding the progression of $\mathrm{HNSI}$, there was no significant relation between the number of involved space and timing of starting treatment (Fig-2)

FIG 3: Recovery time in relation with number of involved space $(n=49)$.

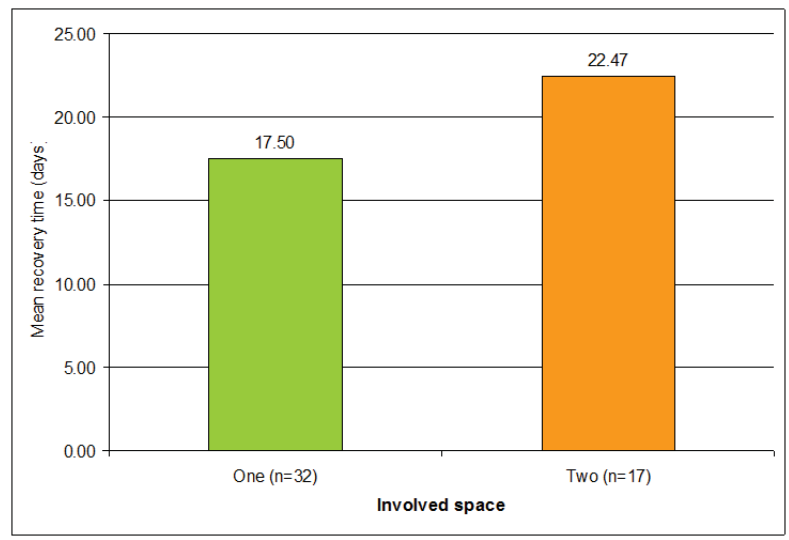

$\mathrm{p}=0.04, \mathrm{t}=2.204$

$P$ value reached from unpaired student $t$-test, statistically significant difference between one and two space involvement. But there was significant co-relation with mean recovery time and number of involved space. The mean time was 17.50 days when there was one space involved and it was 22.47 days when number of involved spaces was two.
Figure -4: Shows correlation between recovery time and timing of starting treatment.

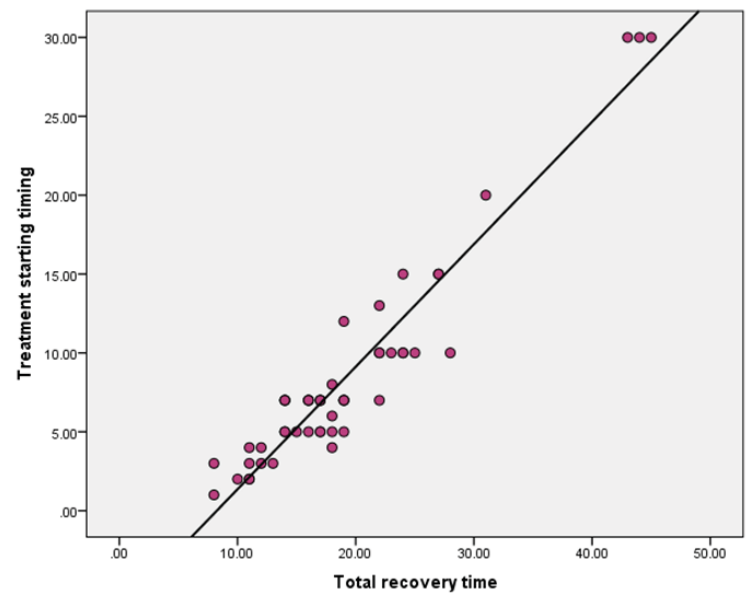

** Time in days

${ }^{* *}$ Correlation is significant at the 0.001 level.

According to the fig-4, there was strong correlation between recovery time and timing of starting treatment as recovery time increase significantly with delay of taking appropriate treatment.

\section{Discussion}

In this prospective observational study of fifty patients, caries was the most frequent cause (60\%) of space infection, which supports the previous study of Thomas R. Flynn et al (2006) that was 65\% and also study of Manal Al-Malika and Maha Al-Sarheedb which was $88 \%^{5,6}$.

Time elapsed in between starting of symptoms and initiation of adequate treatment (timing of starting treatment) was assessed to find its correlation with its distribution and outcome. The mean timing of starting adequate treatment was $8.52( \pm 6.689)$ days. This delay of starting treatment causing increased recovery time as shown in figure 4 which in turn increases sufferings and cost of treatment.

Interestingly in this study, there was no significant relationship in between number of involved space and delay of starting treatment.

However, there was significant correlation in between number of involved space and recovery time in unpaired student $\mathrm{t}$-test $(\mathrm{t}=2 \mathrm{2}$.204). Although this finding has high clinical importance but any similar article was not found. 


\section{Conclusion:}

Information about delay of starting treatment and number of involved spaces can be used as a prognosis predictor in HNSI. Additional rigorously conducted retrospective randomized trials with large sample sizes, full reporting of outcomes are required Steps should have to take to increase awareness of people about the disease like prevention of caries and to take treatment early in this type of disease.

\section{References:}

1. Singh P, Thakur R, Gupta S, Rajput A, Agarwal M , Singh A. ANATOMY OF FACIAL SPACES IN HEAD AND NECK A REVIEW ARTICLE. Journal of Science. 2015;5(4):235237.

2. Kamath MP, Shetty AB, Hegde MC,Suja S, Bhojwani K, Padmanabhan K, Agarwal S, Mathew M, Kumar RM. PRESENTATION AND MANAGEMENT OF DEEPNECK SPACE ABSCESS. Indian Journal of Otolaryngology and Head and Neck Surgery.October-December2003;55(4).

3. Flynn TR. Maxillofacial infections. In: Peter E. Larsen(ed.)Peterson's Principles of oral and maxillofacial surgery. Vol.1. 2nd ed. Hamilton: BC Decker Inc; 2004. P.278-80.

4. Kuriyama T, Lewis MAO and Williams DW. Infections of oral and maxillofacial region. In: Andersson $L$ (ed.)Oral and maxillofacial surgery. West Sussex, Wiley-Blackwell; 2010. P.507.

5. Flynn TR. Maxillofacial infections. In: Peter E. Larsen (ed.) Peterson's Principles of oral and maxillofacial surgery. Vol.1. 2nd ed. Hamilton: BC Decker Inc; 2004. P.278-80.

6. Al-Malika M and Al-Sarheedb M. Pattern of management of oro-facial infection in children: A retrospective. Saudi $\mathrm{J}$ Biol Sci. 2017 Sep 24(6):1375-1379. 